\title{
Low-temperature synthesis of strontium titanate particles with high specific surface area
}

\author{
Kazuya UJIIE ${ }^{1}$, Takashi KOJIMA ${ }^{1, \dagger}$, Kosuke OTA ${ }^{1}$, Shuhei HOSOYA ${ }^{1}$ and Naofumi UEKAWA ${ }^{1}$ \\ ${ }^{1}$ Department of Applied Chemistry and Biotechnology, Graduate School of Engineering, Chiba University, \\ 1-33 Yayoi-cho, Inage-ku, Chiba 263-8522, Japan
}

\begin{abstract}
Strontium titanate $\left(\mathrm{SrTiO}_{3}\right)$ particles are expected to be applied to various catalysts, and many kinds of synthesis procedures of $\mathrm{SrTiO}_{3}$ particles with a high specific surface area have been proposed. This study investigates a synthesis procedure of preparing $\mathrm{SrTiO}_{3}$ particles with a high specific surface area by minimizing the crystallization temperature to the least possible value. The $\mathrm{SrTiO}_{3}$ particles are prepared by maintaining spherical hydrous titania particles with smooth or porous surfaces in highly concentrated strontium hydroxide solutions at $\leq 120^{\circ} \mathrm{C}$. When porous hydrous titania particles are used as the raw material and the $\mathrm{Sr} / \mathrm{Ti}$ ratio in the reaction solution is set at 10, spherical protrusions of $\mathrm{SrTiO}_{3}$ develop on the surface of the original hydrous titania, even at a low temperature $\left(25^{\circ} \mathrm{C}\right)$. Single-phase $\mathrm{SrTiO}_{3}$ particles with spherical protrusions composed of very fine crystallites are obtained by treatment at $40^{\circ} \mathrm{C}$ for $24 \mathrm{~h}$. These particles have a high BET specific surface area of $237 \mathrm{~m}^{2} \mathrm{~g}^{-1}$. The process developed herein is eco-friendly and effective for fabricating various perovskite-type compounds with a high specific surface area.

(c)2021 The Ceramic Society of Japan. All rights reserved.
\end{abstract}

Key-words : Strontium titanate, Porous, Hydrothermal, Low temperature, Particle

[Received June 16, 2021; Accepted August 24, 2021]

\section{Introduction}

Strontium titanate $\left(\mathrm{SrTiO}_{3}\right)$ is used in various applications, such as electronic devices, ${ }^{1)-4)}$ gas sensors, ${ }^{5), 6)}$ thermoelectric conversion materials, ${ }^{7-9)}$ and pigments, ${ }^{10}$ because of its thermal and chemical stabilities, ferroelectricity, semiconductivity, and thermoelectric properties. In the recent years, the application of $\mathrm{SrTiO}_{3}$ as catalysts ${ }^{11), 12}$ ) and photocatalysts ${ }^{13), 14)}$ has widely progressed, especially in water-splitting photocatalysts according to the Zscheme, ${ }^{15}$ ) owing to the ease in doping of dissimilar metals and the appropriate band structure. A high specific surface area is generally required to utilize solid materials as catalysts. Therefore, numerous synthesis methods for preparing $\mathrm{SrTiO}_{3}$ nanoparticles with a high specific surface have been reported. ${ }^{16)-20)}$ For example, Zhang et al. obtained $\mathrm{SrTiO}_{3}$ nanoparticles with a Brunauer-EmmettTeller specific surface area $\left(S_{\mathrm{BET}}\right)$ of $42 \mathrm{~m}^{2} \mathrm{~g}^{-1}$ using a hydrothermal method. ${ }^{21)}$ Sulaeman et al. and Silva et al. obtained such nanoparticles using a microwave-assisted solvothermal reaction $\left(S_{\mathrm{BET}}: 65 \mathrm{~m}^{2} \mathrm{~g}^{-1}\right)^{22)}$ and a modified polymeric precursor method ( $S_{\mathrm{BET}}$ : $83 \mathrm{~m}^{2} \mathrm{~g}^{-1}$ using), $\left.{ }^{23}\right)$ respectively. However, nanoparticles are difficult to handle and obtain uniform dispersions in solvents, and recovering these particles from suspensions as an as-prepared powder

Corresponding author: T. Kojima; E-mail: tkojima@ faculty. chiba-u.jp is challenging. Furthermore, there have been some concerns about the toxicity of nanomaterials. ${ }^{24), 25)}$ On the contrary, particles with both sub-micron to micron diameters and high specific surface area have been realized by constructing porous ${ }^{26)-30)}$ or hierarchical structures ${ }^{27), 31)-33)}$ on the particle surface. Such structures can be achieved using templates, ${ }^{26)}$ solvothermal, ${ }^{31), 32)}$ molten salt, ${ }^{29)}$ or hydrothermal methods. ${ }^{27,28), 30), 33)}$ Liu et al. synthesized porous particles with a sub-micron diameter and a maximum $S_{\mathrm{BET}}$ of $434 \mathrm{~m}^{2} \mathrm{~g}^{-1}$ via a molten salt method (however, holding at $205^{\circ} \mathrm{C}$ for 7 days in molten salt was required). ${ }^{29)}$ Using water, the simplest solvent, Pan et al. synthesized particles with an $S_{\mathrm{BET}}$ of $170 \mathrm{~m}^{2} \mathrm{~g}^{-1}$ and an average diameter of approximately $450 \mathrm{~nm}$ through a $4 \mathrm{~h}$ hydrothermal treatment involving hydrous titania particles at $140{ }^{\circ} \mathrm{C} .{ }^{30)}$ This study aims to develop a synthesis procedure for achieving micron-sized $\mathrm{SrTiO}_{3}$ particles with a high specific surface area.

The low-temperature crystallization of $\mathrm{SrTiO}_{3}$ particles has been tried to suppress the decrease in the specific surface area. Using an ionic liquid as the solvent, Alammar et al. synthesized $\mathrm{SrTiO}_{3}$ particles with an $S_{\mathrm{BET}}$ of 62 $\mathrm{m}^{2} \mathrm{~g}^{-1}$ using ultrasound irradiation without a thermal treatment. ${ }^{34)}$ In addition, Yamaguchi et al. reported that $\mathrm{SrTiO}_{3}$ can be crystallized at room temperature by leaving the mixture of "the hydrous titania gel having more $\mathrm{OH}$ groups" with strontium hydroxide powder $\left(S_{\mathrm{BET}}\right.$ was not reported) ${ }^{35)}$ Thus, in the present study, we focused on the 
effect of concentrated strontium hydroxide when obtaining $\mathrm{SrTiO}_{3}$ at low temperatures. In our previous work, we reported a preparation method that achieves uniformly sized hydrous titania particles via titanium butoxide hydrolysis using ammonia and water in a mixed solution of butanol and acetonitrile. ${ }^{36), 37)}$ Hydrous titania particles, especially those prepared with low ammonia and water concentrations, have low chemical stability and become porous when soaked in ethanol by the partial dissolution of the surface part. ${ }^{38)}$ Porous hydrous titania particles are highly reactive and can convert to $\mathrm{SrTiO}_{3}$ particles at $90{ }^{\circ} \mathrm{C}$ in a strontium hydroxide solution, maintaining the particle size and shape of the raw material particles. ${ }^{39)}$ However, the effect of the $\mathrm{Sr}^{2+}$ to $\mathrm{Ti}^{4+}$ ratio $(\mathrm{Sr} / \mathrm{Ti})$ in the reaction system was not examined in our previous study; instead, the concentration ratio was fixed at 1 . Moreover, the core part of the particles was not completely converted to $\mathrm{SrTiO}_{3}$.

In this study, hydrous titania particles with a spherical shape having smooth or porous surfaces were prepared as the starting materials for the $\mathrm{SrTiO}_{3}$ conversion. Their conversion conditions to $\mathrm{SrTiO}_{3}$ by hot water $\left(<100^{\circ} \mathrm{C}\right)$ or hydrothermal treatment $\left(\geq 100^{\circ} \mathrm{C}\right)$ in strontium hydroxide solutions were widely examined. We refer herein to the treatment lower than $100^{\circ} \mathrm{C}$ as the "hot water treatment." The difference between hydrothermal and hot water treatment in this study is the variation in temperature from 25 to $120^{\circ} \mathrm{C}$ and pressure due to the vapor pressure of water $\left(1.96 \mathrm{~atm}\right.$ at $120^{\circ} \mathrm{C}$ ) and the operation is exactly the same. However, treatments below $100^{\circ} \mathrm{C}$ cannot be called "hydrothermal," so we individually distinguished the treatment as "hot water" treatment. An important advantage of the "hot water treatment" (compared with hydrothermal treatments) is that we can perform the treatment without a costly pressure-resistant container. Moreover, crystallization at low temperatures is beneficial in terms of the environment and cost. We particularly focused on the effect of the concentrated strontium hydroxide for obtaining particles of single-phase $\mathrm{SrTiO}_{3}$ with a high specific surface area by lowering the crystallization temperature to the least possible temperature.

\section{Material and methods}

\subsection{Synthesis of the $\mathrm{SrTiO}_{3}$ particles}

The reagents used in this study were titanium $n$ butoxide, $n$-butanol, acetonitrile, ammonia water (28 wt.\%), strontium hydroxide octahydrate $\left[\mathrm{Sr}(\mathrm{OH})_{2} \cdot 8 \mathrm{H}_{2} \mathrm{O}\right]$, and nitric acid (0.1 M; FUJIFILM Wako Pure Chemical Industries Ltd., Japan). The water used for the synthesis and washing of the particles was prepared by reverse osmosis and electrodeionization (Elix System; Millipore Corp., USA). Two kinds of hydrous titania particles, namely, spherical particles with a smooth surface (hereafter referred to as spherical particles) and those with a porous surface (hereafter referred to as porous particles), were prepared by hydrolyzing titanium butoxide following a published procedure. ${ }^{38)}$ First, two batches of $50 \mathrm{vol} \%$ acetonitrile and 50 vol $\% n$-butanol mixed solvents were prepared. Titanium butoxide was added to one of the mixed solvent systems under a dry $\mathrm{N}_{2}$ atmosphere. Subsequently, ammonia water was added to the other mixed solvent. Both prepared solutions were preheated at $80^{\circ} \mathrm{C}$ using a water bath before initiating the reaction. These two solutions were then mixed and kept at $80^{\circ} \mathrm{C}$ for $30 \mathrm{~min}$ while stirring. Upon mixing, the hydrolysis product precipitated immediately, forming a white suspension. After 30 min of stirring, the precipitates were centrifuged and the supernatant was removed. The remaining precipitates were washed by re-dispersion in ethanol and centrifuged thrice to dissolve the insufficiently polycondensed parts of the particles. The particles were then rinsed thrice in the same manner with water to wash the remaining alcohol. After washing, the particles were dried at $75^{\circ} \mathrm{C}$. Spherical particles with a uniform size were obtained when the concentrations of the starting materials after mixing were set at $0.05 \mathrm{M}$ titanium butoxide, $0.10 \mathrm{M}$ ammonia, and $0.50 \mathrm{M}$ water [Fig. 1(a)]. Meanwhile, a porous structure was constructed at the washing stage with ethanol [Fig. 1(b)] when the concentrations of ammonia and water were changed to 0.02 and $0.31 \mathrm{M}$, respectively.

$\mathrm{SrTiO}_{3}$ particles were prepared by hot water or hydrothermal conversion of the hydrous titania particles. Hydrous titania particles and strontium hydroxide octahydrate were added to water and dispersed ultrasonically. Titanium concentration in the suspension was set to $0.02 \mathrm{M}$. The amount of hydrous titania particles was adjusted according to the water content estimated using thermogravimetry. ${ }^{40}$ ) The suspensions were placed in a PTFE-lined autoclave and either hot water treated or hydrothermally treated. After the treatment, the particles were centrifuged and washed once with dilute nitric acid (approximately $0.1 \mathrm{M})^{39)}$ and twice with water to remove the unreacted strontium hydroxide.
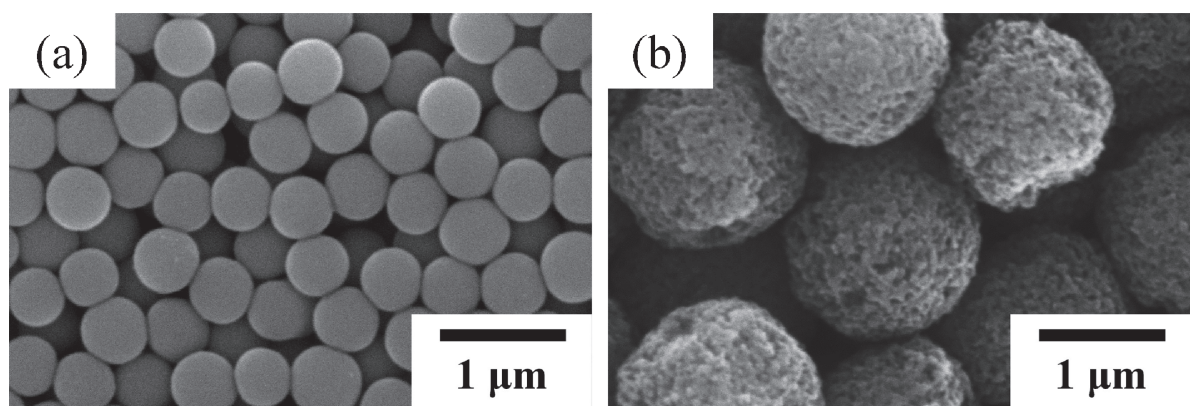

Fig. 1. SEM images of the (a) spherical and (b) porous hydrous titania particles. 


\subsection{Characterization}

The crystalline phases were identified with X-ray diffractometry (XRD; MiniFlex, Rigaku Co. and MXP3; MacScience) using $\mathrm{Cu} \mathrm{K} \alpha$ radiation. The sample morphologies were observed using scanning electron microscopy (SEM; JSM-6510, JEOL, Ltd.) and transmission electron microscopy (TEM; H-7650A, HITACHI, Ltd.). The water content of the hydrous titania particles was determined using thermogravimetry (TG8120; Rigaku Co.). The $S_{\mathrm{BET}}$ and the $\mathrm{N}_{2}$ adsorption-desorption isotherms of the samples were measured using an automatic specific surface area/pore size distribution analyzer (BELSORP-max; MicrotracBEL Co.).

\section{Result and discussion}

In a previous study, we fixed the concentration ratio ( $\mathrm{Sr} / \mathrm{Ti}$ ) to 1 . In this condition, we needed $120^{\circ} \mathrm{C}$ for $24 \mathrm{~h}$ to form the $\mathrm{SrTiO}_{3}$ phase on the spherical hydrous titania particles. Moreover, a small amount of hydrous titania remained in the central part of the particles treated under this condition. ${ }^{39)}$ Figures $\mathbf{2}$ and $\mathbf{3}$ show the XRD patterns and the SEM images of the hydrothermally treated spherical hydrous titania particles, respectively, in aqueous solutions with various strontium hydroxide concentrations. The hydrothermal treatment condition was set at $120^{\circ} \mathrm{C}$ for $24 \mathrm{~h}$. After the hydrothermal treatment, the $\mathrm{SrTiO}_{3}$ phase formation was confirmed, regardless of the $\mathrm{Sr} / \mathrm{Ti}$ ratio.

The SEM images showed that the particles hydrothermally treated under the $\mathrm{Sr} / \mathrm{Ti}=1$ condition maintained the size and the shape of the original spherical hydrous titania particles. However, with the increasing Sr/Ti ratio, the particle shape tended to collapse, and the particles prepared under the $\mathrm{Sr} / \mathrm{Ti}=10$ condition could not maintain the diameter of the original hydrous titania particles. Two types of reaction mechanisms were proposed for converting titania particles to perovskite-type compounds in aqueous solution systems. ${ }^{41)-43)}$ The first type is the in situ reaction mechanism, in which alkaline-earth metal ions react on the titania surface, and the crystallization continues with diffusion of the alkaline-earth metal ions inside the particles. The diffused $\mathrm{Sr}$ ions react with the titanium source and converted to the $\mathrm{SrTiO}_{3}$ inside of the particle. The second type is the dissolution-precipitation reaction mechanism, in which hydrous titania particles are first dissolved in the solvent (aqueous solution of Sr ions), and the dissolved $\mathrm{Ti}$ species react with alkaline-earth metal ions and the crystals of a perovskite-type compound are formed by homogeneous nucleation or heterogeneous nucleation on titania particles. In the present case, the in situ reaction mechanism was dominant when the $\mathrm{Sr} / \mathrm{Ti}$ ratio was set at 1 because the original shape of hydrous titania was

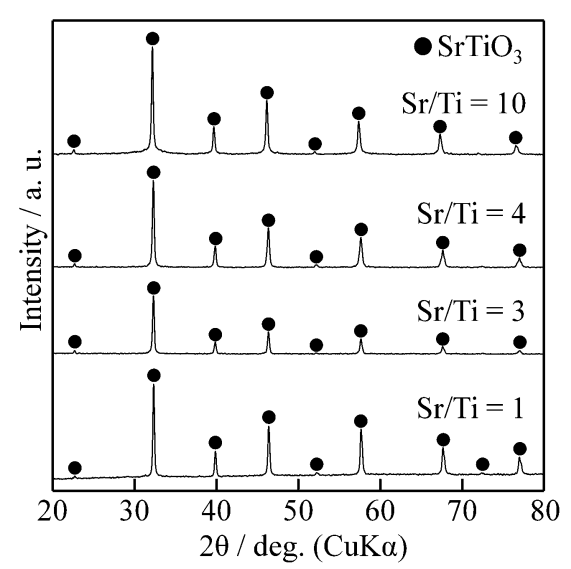

Fig. 2. XRD patterns of the spherical particles after hydrothermal treatment at $120^{\circ} \mathrm{C}$ for $24 \mathrm{~h}$ with various $\mathrm{Sr} / \mathrm{Ti}$ ratios $(\mathrm{Sr} / \mathrm{Ti}=1-10)$.
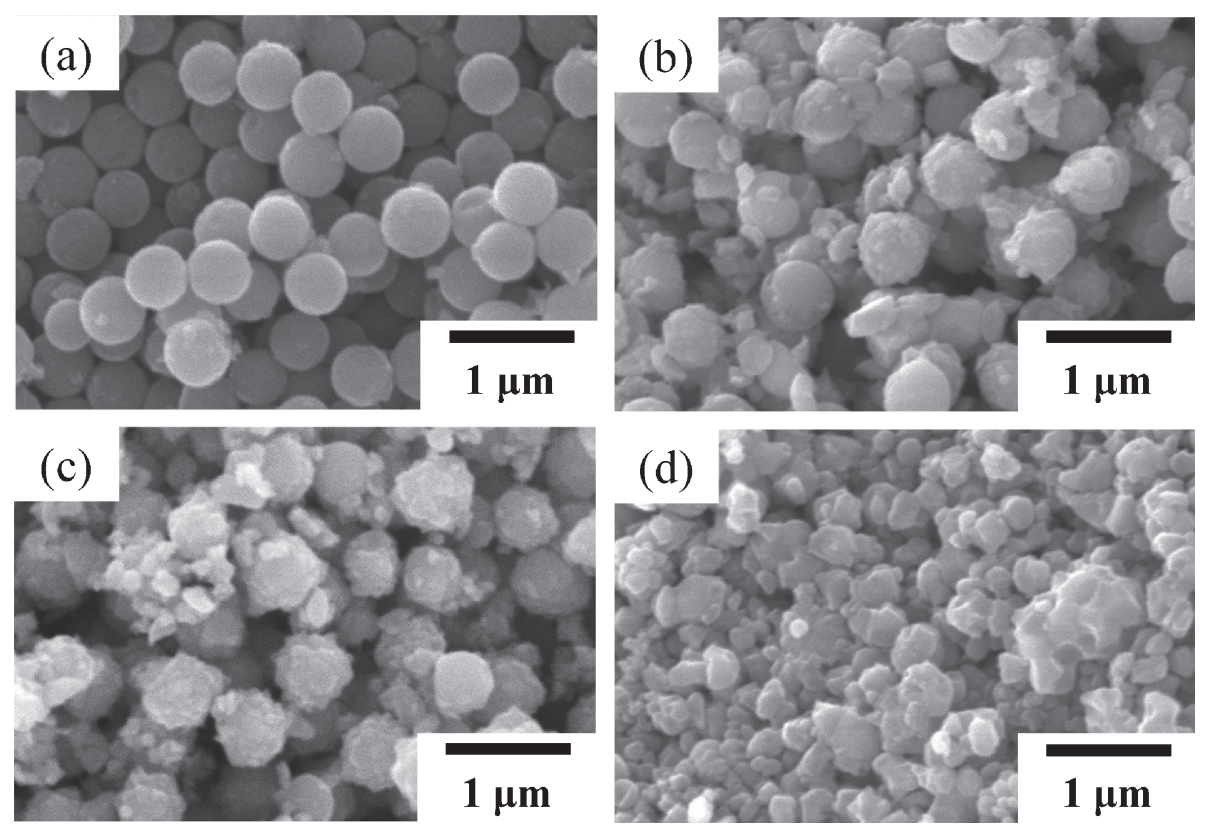

Fig. 3. SEM images of the spherical particles after hydrothermal treatment at $120^{\circ} \mathrm{C}$ for $24 \mathrm{~h}$ with various $\mathrm{Sr} / \mathrm{Ti}$ ratios: (a) $\mathrm{Sr} / \mathrm{Ti}=1$, (b) $\mathrm{Sr} / \mathrm{Ti}=3$, (c) $\mathrm{Sr} / \mathrm{Ti}=4$, and (d) $\mathrm{Sr} / \mathrm{Ti}=10$. 
maintained. When the $\mathrm{Sr} / \mathrm{Ti}$ ratio in the reaction system was set at a high value, a heterogeneous nucleation of the $\mathrm{SrTiO}_{3}$ microcrystals must have occurred on the original hydrous titania particles because of the high $\mathrm{Sr}$ ion concentration, even though the amount of titanium species dissolved in the aqueous solution was very small.

When porous hydrous particles were employed as the starting materials, and the concentration ratio $(\mathrm{Sr} / \mathrm{Ti})$ was set at 1 , we needed the hot water treatment condition of $90{ }^{\circ} \mathrm{C}$ for $48 \mathrm{~h}$ to obtain the $\mathrm{SrTiO}_{3}$ phase. ${ }^{39)}$ Figures 4 and 5 show the XRD patterns and the SEM images of the hot water-treated porous hydrous titania particles, respectively, in aqueous solutions with various strontium hydroxide concentrations. The hot water treatment condition was set at $90{ }^{\circ} \mathrm{C}$ for $48 \mathrm{~h}$. After the treatment, the $\mathrm{SrTiO}_{3}$ formation was confirmed, regardless of the $\mathrm{Sr} / \mathrm{Ti}$ ratio. The SEM observation confirmed that after the hot water treatment,

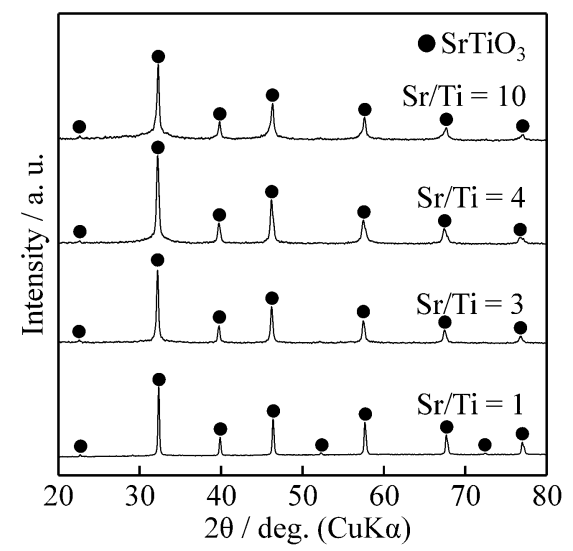

Fig. 4. XRD patterns of the porous particles after hot water treatment at $90^{\circ} \mathrm{C}$ for $48 \mathrm{~h}$ with various $\mathrm{Sr} / \mathrm{Ti}$ ratios $(\mathrm{Sr} / \mathrm{Ti}=$ $1-10)$. the particles almost kept the original morphology of the porous hydrous titania particles used as the starting materials when the $\mathrm{Sr} / \mathrm{Ti}$ ratio in the reaction system was set at 1. On the contrary, when the $\mathrm{Sr} / \mathrm{Ti}$ ratio was set at a higher value, the particle morphology was drastically changed. Small spherical protrusions were newly formed, surrounding the original particles.

Figures 6 and 7 show the XRD patterns and the SEM images of the hot water-treated porous hydrous titania particles, respectively, at $90{ }^{\circ} \mathrm{C}$ for various treatment times. $\mathrm{The} \mathrm{Sr} / \mathrm{Ti}$ ratio in the reaction system was set at 10 . In this case, the porous hydrous particles were converted to $\mathrm{SrTiO}_{3}$ even with the short treatment time of $2 \mathrm{~h}$. The halfwidths of the XRD peaks became narrower with a prolonged treatment time. The SEM image illustrated small spherical protrusions forming on the particles treated for $2 \mathrm{~h}$. Their appearance did not change much even after $48 \mathrm{~h}$ treatment. These results showed that the protrusions formed at the initial crystallization stage and only the $\mathrm{SrTiO}_{3}$ crystallites grew with the treatment time without changing the outer shape of the protrusions.

The $\mathrm{SrTiO}_{3}$ phase was obtained at a short treatment time when the $\mathrm{Sr} / \mathrm{Ti}$ ratio was set at 10; thus, we tried lowtemperature crystallization as the next step. Figures 8(a) and 9 show the XRD patterns and SEM images of the hot water-treated porous hydrous titania particles at various temperatures for $24 \mathrm{~h}$. Figure 8(b) presents the XRD patterns of the particles additionally annealed at $600{ }^{\circ} \mathrm{C}$ for $2 \mathrm{~h}$ after the hydrothermal treatment. In this case, at $40^{\circ} \mathrm{C}$ and lower, strontium hydroxide did not dissolve completely in the aqueous solution, and the precipitations of the solid strontium hydroxide remained in a saturated aqueous solution of the $\mathrm{Sr}$ ion. When the porous hydrous titania particles were treated in a saturated aqueous solution of the $\mathrm{Sr}$ ion, the $\mathrm{SrTiO}_{3}$ phase was formed, even
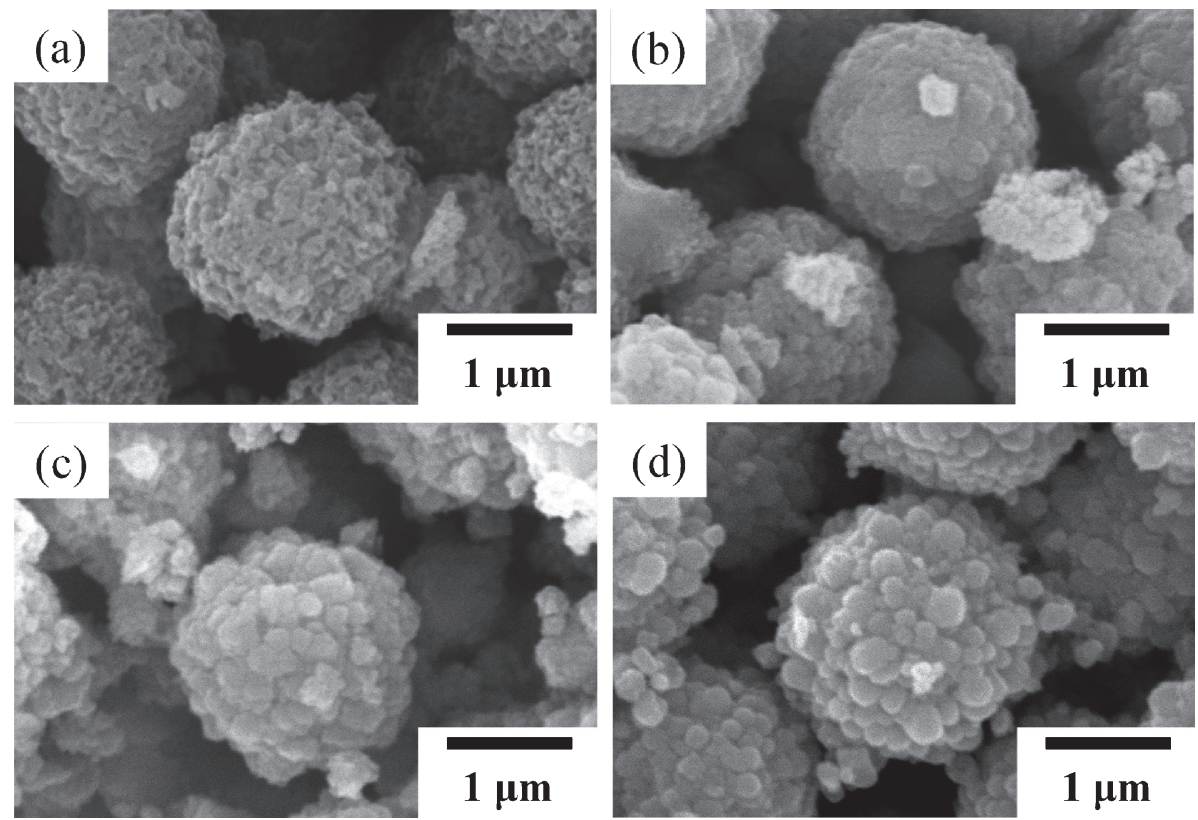

Fig. 5. SEM images of the porous particles after hot water treatment at $90^{\circ} \mathrm{C}$ for $48 \mathrm{~h}$ with various $\mathrm{Sr} / \mathrm{Ti}$ ratios: (a) $\mathrm{Sr} / \mathrm{Ti}=1$, (b) $\mathrm{Sr} / \mathrm{Ti}=3$, (c) $\mathrm{Sr} / \mathrm{Ti}=4$, and (d) $\mathrm{Sr} / \mathrm{Ti}=10$. 


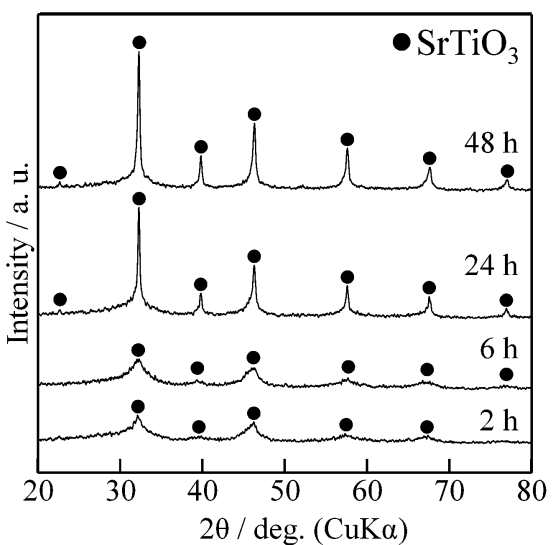

Fig. 6. XRD patterns of the porous particles after hot water treatment at $90^{\circ} \mathrm{C}$ for various times $(\mathrm{Sr} / \mathrm{Ti}=10)$.
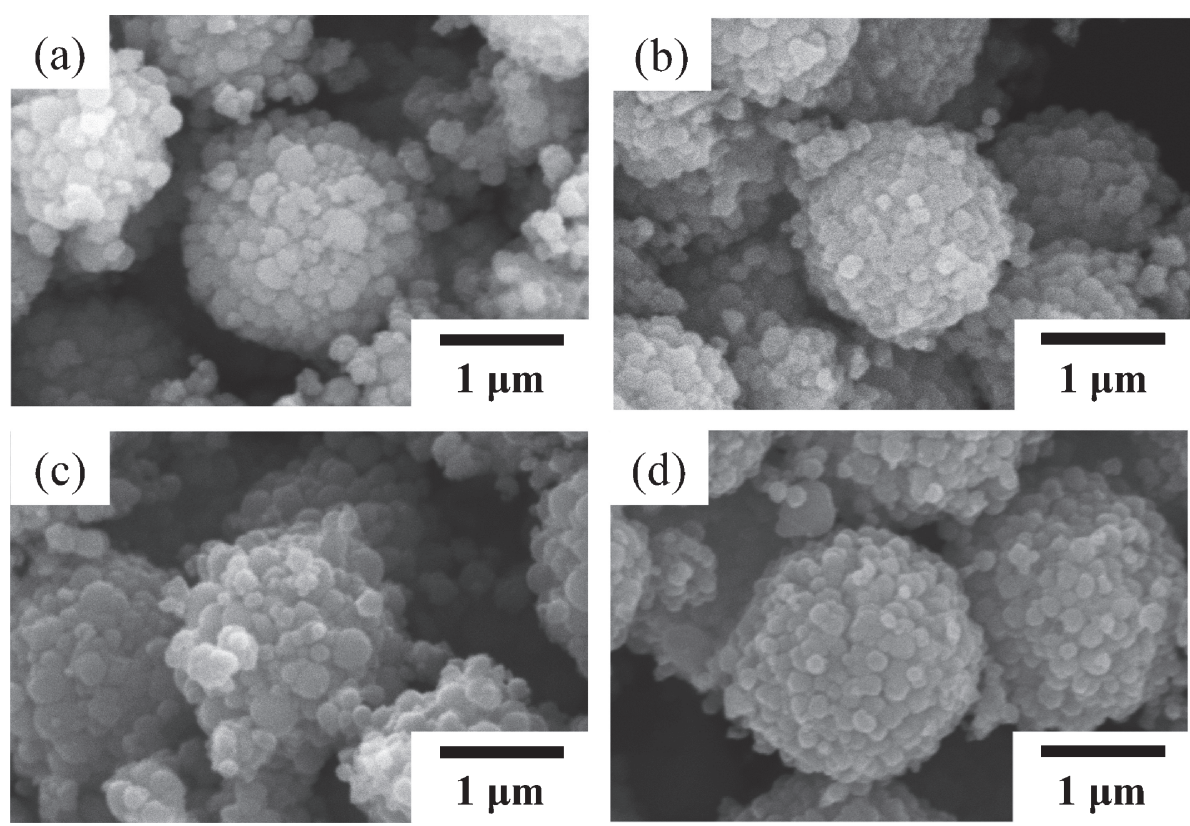

Fig. 7. SEM images of the porous particles after hot water treatment at $90^{\circ} \mathrm{C}$ for (a) $2 \mathrm{~h}$, (b) $6 \mathrm{~h}$, (c) $24 \mathrm{~h}$, and (d) $48 \mathrm{~h}(\mathrm{Sr} / \mathrm{Ti}=10)$.
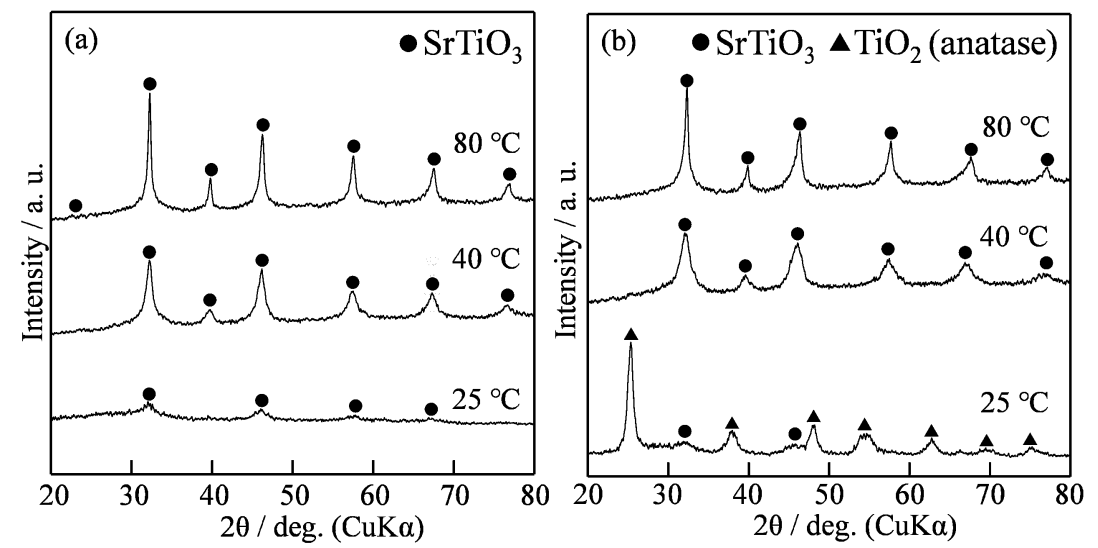

Fig. 8. XRD patterns of the porous particles (a) after hot water treatment at various temperatures for $24 \mathrm{~h}$ and (b) with additional annealing at $600^{\circ} \mathrm{C}$ for $2 \mathrm{~h}(\mathrm{Sr} / \mathrm{Ti}=10)$. 

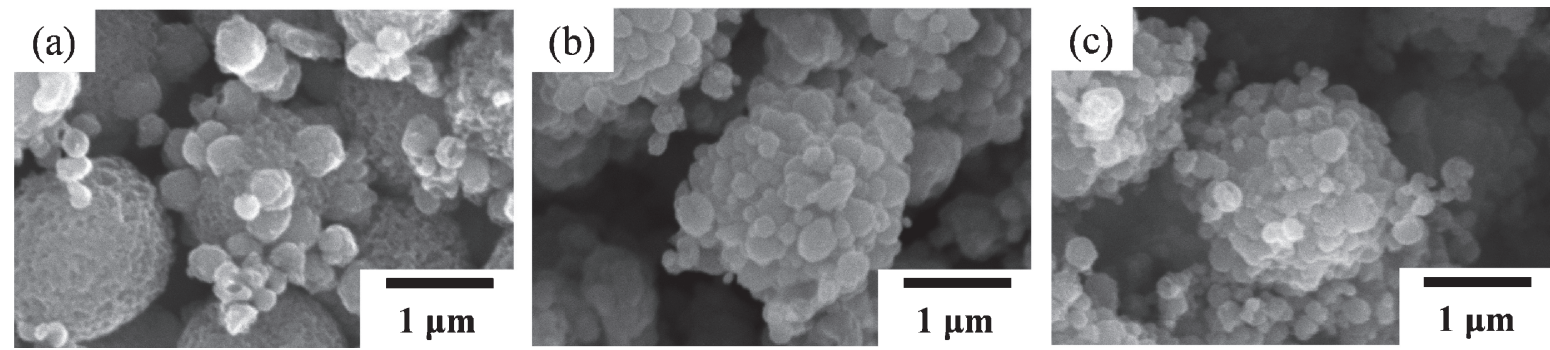

Fig. 9. SEM images of the porous particles after hot water treatment for $24 \mathrm{~h}(\mathrm{Sr} / \mathrm{Ti}=10)$ at (a) $25^{\circ} \mathrm{C}$, (b) $40^{\circ} \mathrm{C}$, and (c) $80^{\circ} \mathrm{C}$.
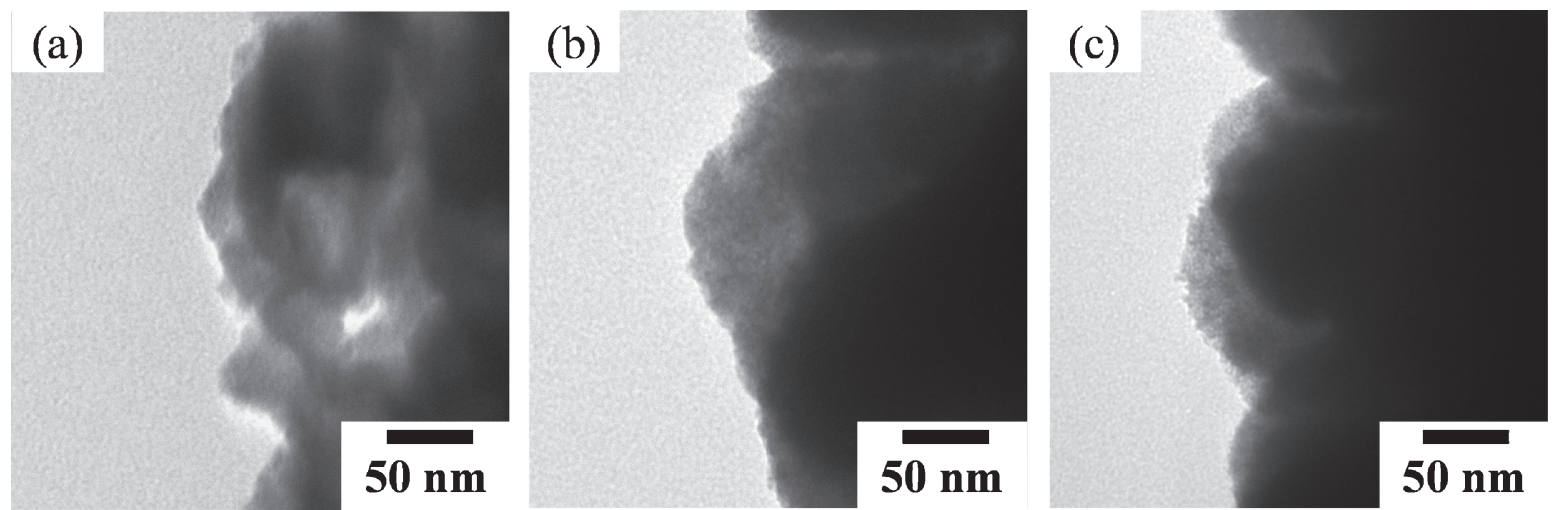

Fig. 10. TEM images of the porous particles (a) hydrous titania, after hot water treatment for $24 \mathrm{~h}(\mathrm{Sr} / \mathrm{Ti}=10)$

(b) at $40^{\circ} \mathrm{C}$ and (c) $80^{\circ} \mathrm{C}$.

Meanwhile, on the particles treated at $25^{\circ} \mathrm{C}$, the spherical protrusions were only locally formed, and the structure of the original particles remained considerably porous. Although the reason for the local formation of the protrusions was not clear, it may attributable to the variation in the chemical stability and microstructure of the surface of the porous hydrous titania because the dissolution of titanium species at the ethanol washing stage was not uniform. The protrusions seemed to be formed only at the low-stability part.

Figure 10 shows the TEM images of the spherical protrusions formed on the porous hydrous titania particles after hot water treatment at 40 or $80^{\circ} \mathrm{C}$ for $24 \mathrm{~h}$. The $\mathrm{Sr} / \mathrm{Ti}$ ratio in the reaction system was set at 10 . The spherical protrusions were composed of fine primary crystallites. The surface of the particles treated at $40^{\circ} \mathrm{C}$ had an aggregate structure of fine primary particles similar to the surface of the hydrous titania particles. The crystallites prepared at $80^{\circ} \mathrm{C}$ were slightly larger than those prepared at $40{ }^{\circ} \mathrm{C}$. This result is consistent with the crystallite growth expected from the half-width of the XRD peaks.

Figure 11 shows the $\mathrm{N}_{2}$ adsorption-desorption isotherms of the single-phase $\mathrm{SrTiO}_{3}$ particles with spherical protrusions around them prepared with a high $\mathrm{Sr} / \mathrm{Ti}$ ratio of 10 . The treatment conditions were at $40^{\circ} \mathrm{C}$ for $24 \mathrm{~h}$. The isotherms of the non-treated porous hydrous titania particles and the porous $\mathrm{SrTiO}_{3}$ particles prepared by hot water treatment at $90^{\circ} \mathrm{C}$ for $48 \mathrm{~h}$ with the $\mathrm{Sr} / \mathrm{Ti}$ ratio of $1^{39)}$ were also shown for comparison. The $S_{\mathrm{BET}}$ of the $\mathrm{SrTiO}_{3}$ particles with spherical protrusions estimated from the isotherm

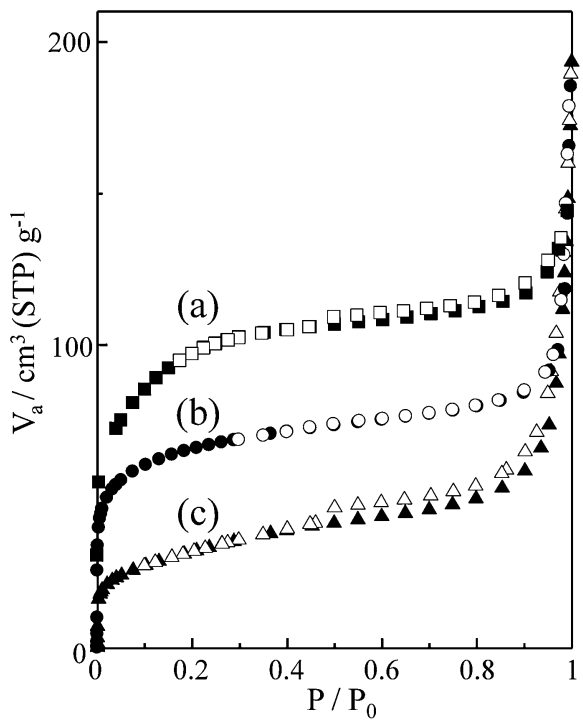

Fig. 11. $\mathrm{N}_{2}$ adsorption-desorption isotherms of (a) porous hydrous titania, ${ }^{39)}$ (b) $\mathrm{SrTiO}_{3}$ particles prepared at $40{ }^{\circ} \mathrm{C}$ for $24 \mathrm{~h}$ with the $\mathrm{Sr} / \mathrm{Ti}$ ratio of 10 , and (c) $\mathrm{SrTiO}_{3}$ particles prepared at $90^{\circ} \mathrm{C}$ for $48 \mathrm{~h}$ with the $\mathrm{Sr} / \mathrm{Ti}$ ratio of $1^{39}$ ) (closed symbols $=$ adsorption; open symbols $=$ desorption).

was $237 \mathrm{~m}^{2} \mathrm{~g}^{-1}$. Although this value was lower than that of the porous hydrous titania $\left(357 \mathrm{~m}^{2} \mathrm{~g}^{-1}\right),{ }^{39)}$ they had approximately twice the value of the porous $\mathrm{SrTiO}_{3}$ particles prepared at $90^{\circ} \mathrm{C}$ for $48 \mathrm{~h}$ with the $\mathrm{Sr} / \mathrm{Ti}$ ratio of 1 $\left(115 \mathrm{~m}^{2} \mathrm{~g}^{-1}\right) .^{39)}$ The specific surface area of the particles treated at $40^{\circ} \mathrm{C}$ is lower than that of the particles prepared 
using the molten salt method. ${ }^{29)}$ However, as mentioned in the Introduction, this area is quite large for micron-sized single-phase $\mathrm{SrTiO}_{3}$ particles. Furthermore, the particles were obtained at a temperature of $40^{\circ} \mathrm{C}$ without the use of special solvents or ultrasound techniques. On the nitrogen adsorption-desorption isotherms of the $\mathrm{SrTiO}_{3}$ particles with spherical protrusions [Fig. 11(b)], the rapid increase in the adsorption amount at a low relative pressure region indicated the existence of micropores. Although this rapid increase in the adsorption amount was smaller than that of the porous hydrous titania [Fig. 11(a)], it was much larger than that of the porous $\mathrm{SrTiO}_{3}$ particles prepared at $90^{\circ} \mathrm{C}$ for $48 \mathrm{~h}$. This difference in the porous structure affected the specific surface area of the particles. The TEM image [Fig. 10(b)] depicted those spherical protrusions were constructed with ultrafine primary crystallites. The spaces between these ultrafine crystallites must correspond to the micropores.

From the obtained results, the formation process of small spherical protrusions is discussed as follows: spherical protrusions observed when the $\mathrm{Sr} / \mathrm{Ti}$ ratio in the reaction system was set at high values cannot be formed via the in situ reaction mechanism. In the initial reaction stage, the top surface parts of the hydrous titania particles would dissolve in the Srion solution to some extent. This amount of dissolution is expected to be larger for porous particles with a low chemical stability and a larger surface area in contact with the aqueous solution than that for the spherical ones. The titanium species produced by the dissolution will immediately react with the high $\mathrm{Sr}$ ion concentration and lead to a rapid heterogeneous nucleation in or around the macropores of the porous particles with a rough surface. This rapid heterogeneous nucleation all around the porous hydrous titania particles should result in the formation of spherical protrusions consisting of fine crystallites.

The $\mathrm{SrTiO}_{3}$ particles with a high specific surface area prepared herein could be utilized for various catalysis by incorporating trace metal ion doping ${ }^{44)}$ or co-catalyst deposition. ${ }^{11)}$ Moreover, this process is expected to be applied for the low-temperature synthesis of various composite oxide particles with a high specific surface area.

\section{Conclusions}

Single-phase $\mathrm{SrTiO}_{3}$ particles with a high $S_{\text {BET }}$ of 237 $\mathrm{m}^{2} \mathrm{~g}^{-1}$ were obtained at a low temperature of $40^{\circ} \mathrm{C}$ by soaking porous hydrous titania particles in a concentrated $\mathrm{Sr}$ ion aqueous solution. In the presence of highly concentrated $\mathrm{Sr}$ ions, the porous hydrous titania particles were converted to particles with a characteristic structure, in which small spherical protrusions surrounded the original particles. This method is advantageous for obtaining micron-sized composite oxide particles with high specific surface area at low temperatures without requiring special equipment such as pressure resistant containers or ultrasound-irradiation devices.

Conflict of interests The authors declare that there is no conflict of interest.
Acknowledgment This work was supported by JSPS KAKENHI Grant Number 21K05223. The authors would like to thank Enago (www.enago.jp) for the English language review.

\section{Reference}

1) O. A. Marina, N. L. Canfield and J. W. Stevenson, Solid State Ionics, 149, 21-28 (2002). doi:10.1016/S01672738(02)00140-6

2) H. Tanaka, J. Zhang and T. Kawai, Phys. Rev. Lett., 88, 027204 (2002). doi:10.1103/PhysRevLett.88.027204

3) J. H. Haeni, P. Irvin, W. Chang, R. Uecker, P. Reiche, Y. L. Li, S. Choudhury, W. Tian, M. E. Hawley, B. Craigo, A. K. Tagantsev, X. Q. Pan, S. K. Streiffer, L. Q. Chen, S. W. Kirchoefer, J. Levy and D. G. Schlom, Nature, 430, 758-761 (2004). doi:10.1038/nature02773

4) N. Nuraje and K. Su, Nanoscale, 5, 8752-8780 (2013). doi:10.1039/c3nr02543h

5) W. Menesklou, H.-J. Schreiner, K. H. Härdtl and E. Ivers-Tiffée, Sensor. Actuat. B-Chem., 59, 184-189 (1999). doi:10.1016/S0925-4005(99)00218-X

6) R. Moos, N. Izu, F. Rettig, S. Reiss, W. Shin and I. Matsubara, Sensors-Basel, 11, 3439-3465 (2011). doi:10.3390/s110403439

7) H. Ohta, Phys. Status Solidi B, 245, 2363-2368 (2008). doi:10.1002/pssb.200844248

8) K. Koumoto, Y. F. Wang, R. Z. Zhang, A. Kosuga and R. Funahashi, Annu. Rev. Mater. Res., 40, 363-394 (2010). doi:10.1146/annurev-matsci-070909-104521

9) J. W. Fergus, J. Eur. Ceram. Soc., 32, 525-540 (2012). doi:10.1016/j.jeurceramsoc.2011.10.007

10) J. Luxová, P. Šulcová and M. Trojan, J. Therm. Anal. Calorim., 93, 823-827 (2008). doi:10.1007/s10973008-9329-z

11) L. Saputra, T. Kojima, T. Hara, N. Ichikuni and S. Shimazu, Mol. Catal., 453, 132-138 (2018). doi:10. 1016/j.mcat.2018.04.023

12) L. Saputra, T. Sato, T. Kojima, T. Hara, N. Ichikuni and S. Shimazu, ACS Omega, 3, 17528-17531 (2018). doi:10.1021/acsomega.8b02622

13) E. Grabowska, Appl. Catal. B-Environ., 186, 97-126 (2016). doi:10.1016/j.apcatb.2015.12.035

14) T. H. Chiang, H. Lyu, T. Hisatomi, Y. Goto, T. Takata, M. Katayama, T. Minegishi and K. Domen, ACS Catal., 8, 2782-2788 (2018). doi:10.1021/acscatal.7b04264

15) Z. Wang, C. Li and K. Domen, Chem. Soc. Rev., 48, 2109-2125 (2019). doi:10.1039/c8cs00542g

16) M. Niederberger, G. Garnweitner, N. Pinna and M. Antonietti, J. Am. Chem. Soc., 126, 9120-9126 (2004). doi:10.1021/ja0494959

17) Y. Li, X. P. Gao, G. R. Li, G. L. Pan, T. Y. Yan and H. Y. Zhu, J. Phys. Chem. C, 113, 4386-4394 (2009). doi:10. $1021 /$ jp810805f

18) F. Dang, K. Mimura, K. Kato, H. Imai, S. Wada, H. Haneda and M. Kuwabara, CrystEngComm, 13, 38783883 (2011). doi:10.1039/c1ce05296a

19) K. Kato, F. Dang, K. Mimura, Y. Kinemuchi, H. Imai, S. Wada, M. Osada, H. Haneda and M. Kuwabara, $A d v$. Powder Technol., 25, 1401-1414 (2014). doi:10.1016/ j.apt.2014.02.006

20) W. F. Zhang, Z. Yin, M. S. Zhang, Z. L. Du and W. C. Chen, J. Phys.-Condens. Mat., 11, 5655-5660 (1999). doi:10.1088/0953-8984/11/29/312 
21) Y. B. Zhang, L. Zhong and D. P. Duan, J. Mater. Sci., 51, 1142-1152 (2016). doi:10.1007/s10853-015-9445-7

22) U. Sulaeman, S. Yin and T. Sato, Appl. Catal. BEnviron., 102, 286-290 (2011). doi:10.1016/j.apcatb. 2010.12.013

23) L. F. Da Silva, L. J. Q. Maia, M. I. B. Bernardi, J. A. Andrés and V. R. Mastelaro, Mater. Chem. Phys., 125, 168-173 (2011). doi:10.1016/j.matchemphys.2010.09. 001

24) S. Sharifi, S. Behzadi, S. Laurent, M. L. Forrest, P. Stroeve and M. Mahmoudi, Chem. Soc. Rev., 41, 23232343 (2012). doi:10.1039/c1cs15188f

25) A. Cox, P. Venkatachalam, S. Sahi and N. Sharma, Plant Physiol. Bioch., 110, 33-49 (2017). doi:10.1016/ j.plaphy.2016.08.007

26) D. Yang, Y. Sun, Z. Tong, Y. Nan and Z. Jiang, J. Hazard. Mater., 312, 45-54 (2016). doi:10.1016/ j.jhazmat.2016.03.032

27) G. Canu and V. Buscaglia, CrystEngComm, 19, 38673891 (2017). doi:10.1039/C7CE00834A

28) Y. Wang, H. Xu, X. Wang, X. Zhang, H. Jia, L. Zhang and J. Qiu, J. Phys. Chem. B, 110, 13835-13840 (2006). doi:10.1021/jp061597t

29) H. Liu, X. L. Chen, S. C. Yan, Z. S. Li and Z. G. Zou, Eur. J. Inorg. Chem., 2014, 3731-3735 (2014). doi:10. 1002/ejic. 201402280

30) J. H. Pan, C. Shen, I. Ivanova, N. Zhou, X. Z. Wang, W. C. Tan, Q. H. Xu, D. W. Bahnemann and Q. Wang, ACS Appl. Mater. Inter., 7, 14859-14869 (2015). doi:10. 1021/acsami.5b03396

31) M. Zhou, J. Chen, Y. Zhang, M. Jiang, S. Xu, Q. Liang and Z. Li, J. Alloy. Compd., 817, 152796 (2020). doi:10.1016/j.jallcom.2019.152796

32) T. Zhang, T. Doert and M. Ruck, Dalton T., 46, 1421914225 (2017). doi:10.1039/c7dt03024j
33) X.-Y. Lai, C.-R. Wang, Q. Jin, R.-B. Yu and D. Wang, Sci. China Mater., 58, 192-197 (2015). doi:10.1007/ s40843-015-0038-1

34) T. Alammar, V. Smetana, H. Pei, I. Hamm, M. Wark and A. V. Mudring, Adv. Sustain. Syst., 5, 2000180 (2021). doi:10.1002/adsu.202000180

35) Y. Yamaguchi, Y. Kanamaru, M. Fukushima, K. Fujimoto and S. Ito, J. Am. Ceram. Soc., 98, 30543061 (2015). doi:10.1111/jace.13765

36) T. Sugimoto and T. Kojima, J. Phys. Chem. C, 112, 18760-18771 (2008). doi:10.1021/jp8029506

37) T. Kojima and T. Sugimoto, J. Phys. Chem. C, 112, 18445-18454 (2008). doi:10.1021/jp802957e

38) T. Kojima, T. Baba, K. Ota, C. Yukita, K. Inamoto and N. Uekawa, J. Ceram. Soc. Jpn., 124, 1226-1228 (2016). doi:10.2109/jcersj2.16208

39) K. Ujiie, T. Kojima, K. Ota, P. Phuenhinlad, S. Pleuksachat, N. Meethong, T. Itoi and N. Uekawa, Ceram. Int., 46, 6146-6153 (2020). doi:10.1016/ j.ceramint.2019.11.080

40) T. Kojima, I. Yoshida, N. Uekawa and K. Kakegawa, J. Eur. Ceram. Soc., 29, 431-437 (2009). doi:10.1016/ j.jeurceramsoc. 2008.06.017

41) J. O. Eckert, Jr., C. C. Hung-Houston, B. L. Gersten, M. M. Lencka and R. E. Riman, J. Am. Ceram. Soc., 79, 2929-2939 (1996). doi:10.1111/j.1151-2916.1996. tb08728.x

42) R. I. Walton, Chem. Soc. Rev., 31, 230-238 (2002). doi: $10.1039 / \mathrm{b} 105762 \mathrm{f}$

43) D. R. Modeshia and R. I. Walton, Chem. Soc. Rev., 39, 4303-4325 (2010). doi:10.1039/b904702f

44) B. Białobok, J. Trawczyński, T. Rzadki, W. Miśta and M. Zawadzki, Catal. Today, 119, 278-285 (2007). doi:10.1016/j.cattod.2006.08.024 